\title{
Georgii Aleksandrovich Zavarzin, January 28, 1933-September 6, 2011
}

DOI: $10.1134 / \mathrm{S} 0026261711080017$

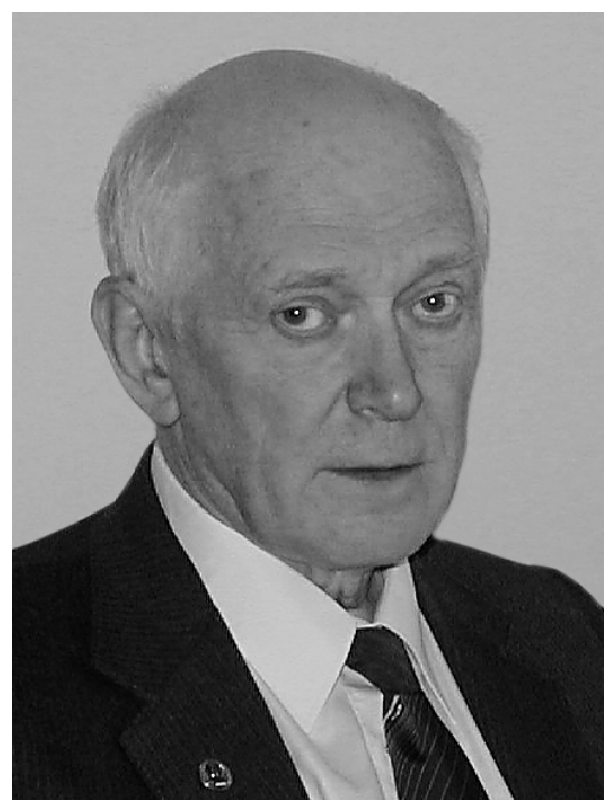

Academician Georgii Zavarzin, an outstanding Russian microbiologist, Head of the Department of the S.N. Winogradsky Institute of Microbiology, Russian Academy of Sciences, passed away September 6, 2011 , at the age of 78 .

Academician Zavarzin was a world-renowned scientist and an indisputable authority in the fields of general microbiology, microbial biodiversity, and global ecology. His studies had a profound effect on the shaping and development of Soviet and Russian microbiology. He discovered and described several new groups of microorganisms, pioneered and developed a systemic approach to studying microbial interactions and the interactions between microorganisms and the environment, and made a seminal contribution to the investigation of extreme habitats as contemporary analogues of the ancient biosphere.

Georgii Zavarzin was the author of more than 300 papers and 10 books; the idea that runs like a golden thread through his scientific heritage is that the activities of microorganisms have a large-scale impact on the entire biosphere. He was a founding father of a leading scientific school that turned out an entire constellation of accredited researchers. His unflagging interest in unveiling the secrets of the microbial world and the zeal he invested in his research have been a source of inspiration for his students and coworkers. $\mathrm{He}$ asserted that the hidden functional potential of each new microorganism should be disclosed, and he maintained that the meaning of microbiological study was to understand the role of microorganisms in the biosphere. His collaborators have described over 100 new taxa of microorganisms and several new types of microbial metabolism. Zavarzin was awarded the Winogradsky Prize by the Presidium of the Russian Academy of Sciences for his studies of chemosynthetic microorganisms. He was also awarded the Bergey Medal in recognition of his outstanding contribution to the exploration of microbial diversity.

Zavarzin has been with the Winogradsky Institute of Microbiology for more than 55 years. As a worldrenowned expert on the functional role of microorganisms in the biosphere, he was on the board of several international programs and committees on problems of global ecology. These included the Scientific Committee on Problems of the Environment (SCOPE), Preparatory Committee for the UNEP Biodiversity Convention, International GeosphereBiosphere Programme (IGBP), Judiciary Committee of the International Union of Microbiological Societies (IUMS), and International Institute for Applied Systems Analysis (IIASA). In 1990-1991, Zavarzin served as the Deputy Chairman of the Soviet State Committee for Environmental Protection and the Deputy Minister of Nature Management and Environmental Protection. More recently, he was one of the directors of the "Origin and Evolution of the Biosphere" basic research program under the Presidium of the Russian Academy of Sciences. In 1983, Zavarzin was awarded the State Order of the Red Banner of Labor and, in 2008, the Order of Friendship.

The immense scope of his mind, his expertise in many fields, his deep devotion to microbiology, and the highest scientific reputation he enjoyed both in Russia and elsewhere place him among the most outstanding contemporary scientists.

The friends, colleagues, and students of Georgii Aleksandrovich Zavarzin mourn his departure and offer their deepest sympathies to his family. 